Submission ID: 43837

\title{
New Geological Data for Model of Sorokin Arch Artinskian Oil Reservoir
}

A.A. Chistyakov* (LLC "RN-UfaNIPIneft"), A.V. Demidov (LLC "RN-UfaNIPIneft"), A.F. Kadyrov (LLC "RN-UfaNIPIneft")

\section{SUMMARY}

This article contains the evaluation of the geological influence over unpredictable and low production rate of Artin age oil reservoir situated at Sorokin Arch. The SCAL results, FMI, logging data and seismic were analyzed during current research. As the result, the new conceptual model was designed including structural and lithological features. As the consequences, the link between production rate and geological features was recognized. 
Новые данные и геологическая модель артинских отложений одного из месторождений Вала Сорокина

А.А. Чистяков* (ООО «РН-УфаНИПИнефть»), А.В. Демидов (ООО «РН-УфаНИПИнефть»), А.Ф. Кадыров (ООО «РН-УфаНИПИнефть»).

\section{Введение}

Продуктивные отложения артинского возраста являются первостепенным объектом разработки на одном из месторождений Вала Сорокина. Однако при разбуривании пласта возникла проблема недостижения запускных дебитов в эксплуатационных скважинах. В рамках данной работы рассматриваются причины недостижения и их связь с геологической моделью пласта P1ar.

При рассмотрении имеющейся информации возникли вопросы относительно утвержденной геологической модели. Выявив острую недостаточность данных, было принято решение об отборе дополнительного кернового материала и проведении широкого комплекса петрофизических и петрографических исследований на нем. Также была проведена переинтерпретация сейсмических данных. Проделанная работа позволила изменить концептуальное представление о структурно-тектоническом и литологическом строении месторождения, по сравнению с ранее утвержденным.

Опираясь на результаты данной работы, был изменен подход к разработке, скорректировано положение скважин и очередность бурения. Фактические запускные дебиты вновь пробуренных скважин достигли проектных или превысили их.

\section{Анализ данных сейсмики}

На первом этапе выполнен анализ доступной сейсмической информации. В результате, по кубу когерентности выявлены множественные неоднородности в пределах пласта. Воспользовавшись инструментом AntTracking, удалось локализовать неоднородности и проследить их на волновой картине (Рис. 1).
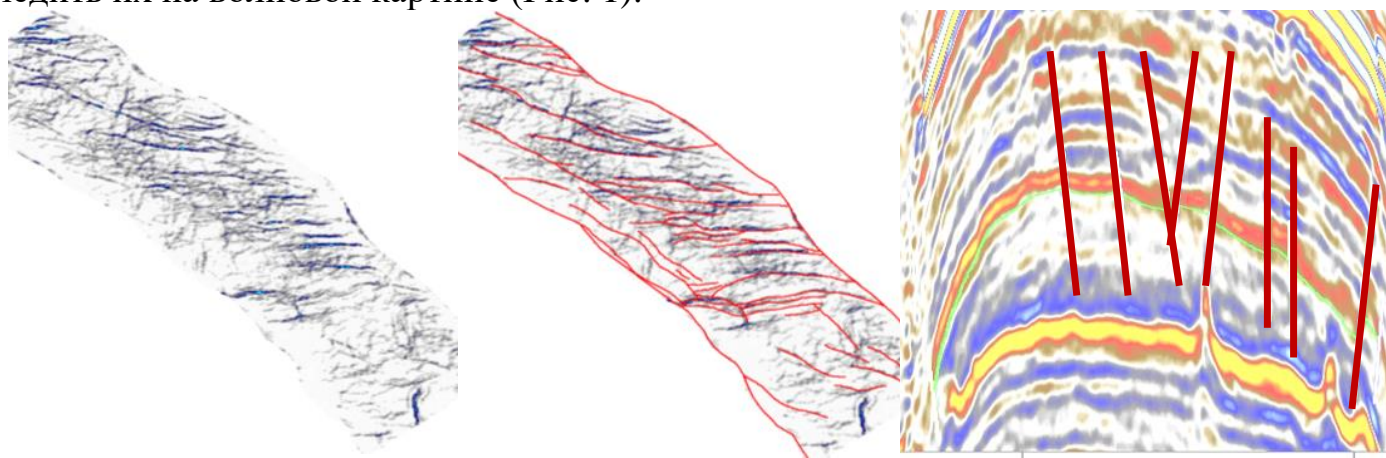

Рисунок 1 Выявленная сеть малоамплитудных тектонических нарушений.

Вновь выявленная сеть разрывных нарушений была рассмотрена с учетом истории тектонического развития. В средне-позднетриасовое время впоследствии транспрессии с востока произошло воздымание территории и заложение разрывных нарушений сдвигового и сбросового характера [1]. Поэтому большая часть разломов отнесена к т.н. кулисообразным сбросам со сдвиговой компонентой (Рис. 1). Кулисообразные разломы представляют наибольший интерес, характеризуются своей открытостью и повышенным фильтрационным потенциалом вследствие природы образования (Рис. 2). Также они расположены относительно близко друг к другу и формируют небольшие блоки, в которых высока вероятность развития трещиноватости как следствия тектонической деструкции от раскрытия кулис. 


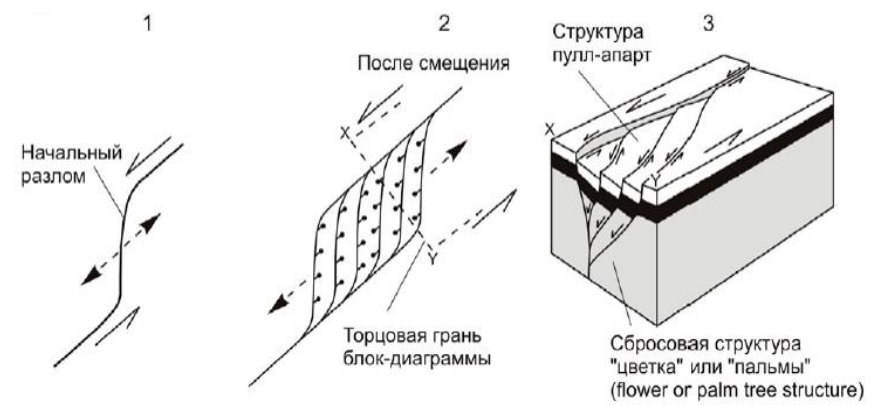

Рисунок 2 Пример образования кулисообразных разрывных нарушений (no R.J. Twiss, E.M. Moores, 2000).

Выявленная сеть разрывных нарушений имеет достаточно убедительную прогнозную силу ввиду подтверждения тектонических нарушений результатами бурения. Как правило, одному нарушению, определенному по сейсмике, соответствовала серия (от 1 до 2) мелкоамплитудных (1-5м) дизъюнктивных нарушений, определяемых по ГИС в эксплуатационных скважинах (Рис. 3). В большинстве случаев по сейсмическим материалам невозможно определить амплитуду нарушений по причине вертикальной разрешенности. Возможно, поэтому в предыдущей модели разломы были не учтены.

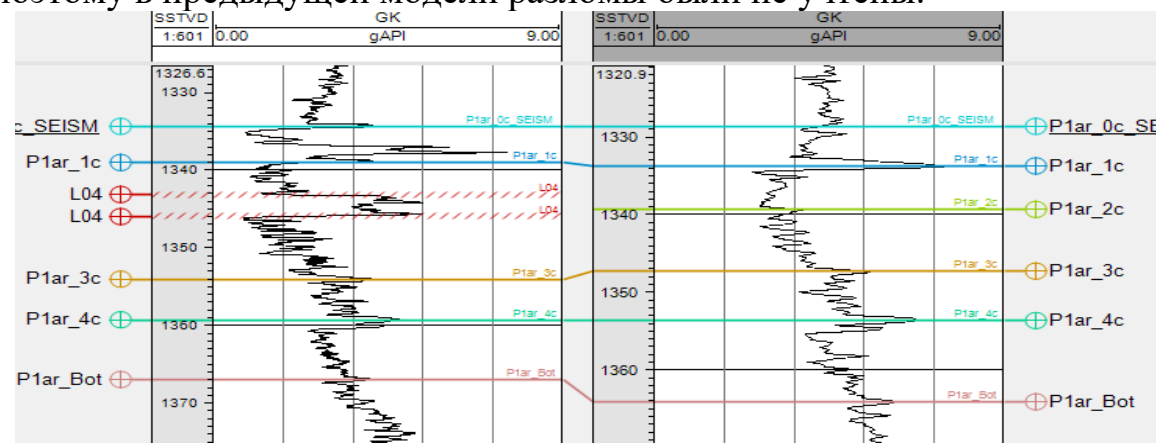

Рисунок 3 Пример скважины, пересекающей вклинивающийся блок (слева L04).

Проведен сравнительный анализ запускных дебитов вновь пробуренных скважин и их местоположения относительно вновь выделенных разломов. Удалось установить, что большинство скважин, показывающих недостижение по запускным дебитам, находятся в относительном удалении от разломов, в то время как скважины, показывающие превышение или соответствие запускным параметрам, пересекают один или несколько разломов (Рис. 4).

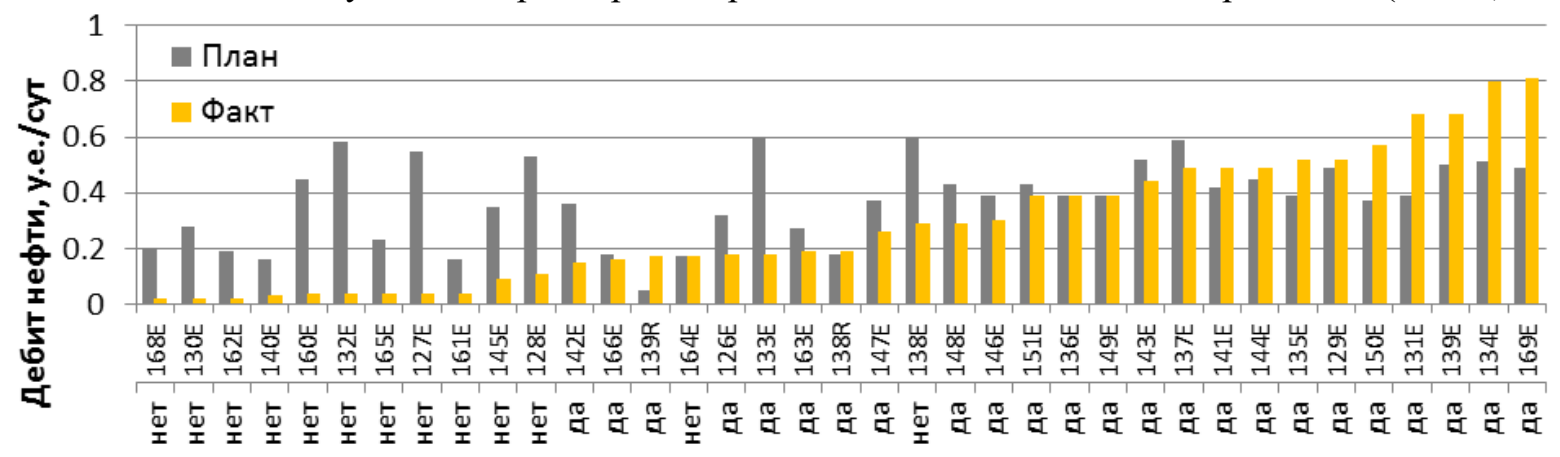

Рисунок 4 Статистика по скважинам, пробуренным с пересечением (да) разломов и без (нет).

Для проверки выдвинутых предположений были рассмотрены дебиты по скважинам, в которых был отобран керн, после чего было проведено сравнение непосредственно кернового материала из скважин $138 R, 139 R$ и $130 E$. Скважины $138 R$ и $139 R$ вскрывают разломы и проходят по зонам тектонических деструкций, приуроченных к кулисообразным разломам. Скважина $130 E$ проходит близко, но всё же за пределами подобной зоны и не вскрывает разлом (Рис. 5). Дебиты во вскрывших разлом скважинах (138R и $139 R)$ превышают дебит в скважине $130 E$, которая разлом не вскрыла (Рис. 4). При рассмотрении кернового материала 
был подмечен факт, что керн из скважин $138 R$ и $139 R$ разрушен в большей мере, нежели керн из скважины $130 E$ (Рис. 6). Данные сведения говорят в пользу гипотезы о наличии проницаемых зон тектонической деструкции, приуроченных к кулисообразным разломам.

Для дальнейшего подтверждения этой теории был выполнен комплекс FMI в двух скважинах: наклонно-направленной в зоне отсутствия тектонических нарушений $140 E$ и горизонтальной, пересекающей тектонические нарушения $126 E$. В разрезе скважины $140 E$ не было выявлено зон трещиноватости. Дебит нефти при испытаниях составил 0,03 у.е./сут. В скважине $126 E$, кроме количественного и качественного подтверждения наличия разломов, были выявлены зоны трещиноватости, сопряженные с разломами (Рис.7). При освоении скважины получен дебит нефти 0,18 у.е./сут. К сожалению, не выполнен комплекс ПГИ в данной скважине, который мог окончательно поставить точку в вопросе связанности выделенных по сейсмическим материалам зон тектонической деструкции и высоких дебитов в эксплуатационных скважинах.

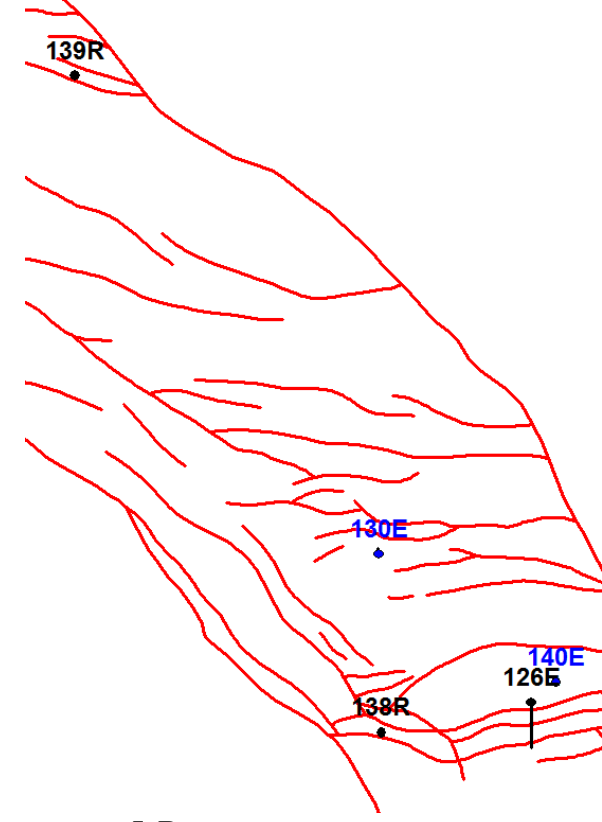

Рисунок 5 Расположение скважин относительно разломов, синие не пересекают, черные пересекают разлом.

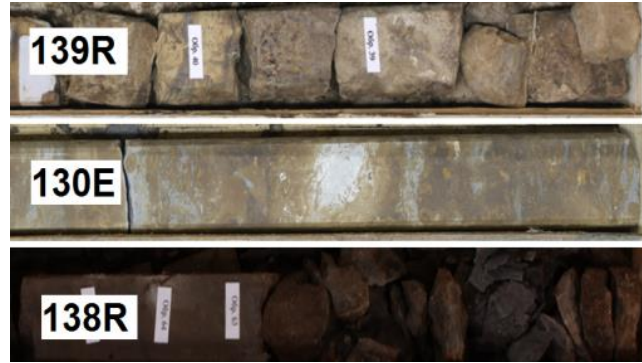

Рисунок 6 Сравнение керна из скважин, попавших в разломы (139R и 138R) и не попавших (130E).

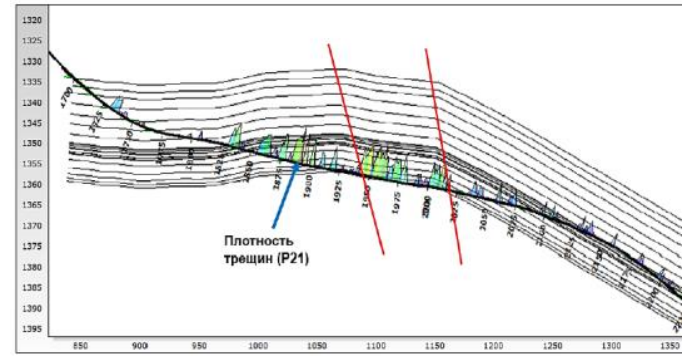

Рисунок 7 Плотность трещин по данным FMI в скв. $126 E$.

\section{Керновые исследования}

Согласно утвержденной модели артинского пласта отложения представлены карбонатными разностями, коллектор выполнен органогенно-детритовыми и тонкомелкозернистыми известняками. Выяснилось, что данная модель принята по данным керна, полученным в 80-е годы прошлого столетия, которые впоследствии были утеряны. Новые исследования, выполненные на керне, отобранном во всем интервале пласта, изменили представление о его литологии и свойствах.

По результатам PCA и анализа шлифов разрез оказался терригенно-карбонатнокремнистым с большей долей биокластовых силицитов (спонголит). В шлифах отмечены многочисленные спикулы губок, которые тесно соседствуют с обломками карбонатных раковин. Характер порового пространства смешанный. В общем объеме преобладают межзерновые поры и внутриформенные, в чистых спонголитах имеются поры выщелачивания, которые занимают порядка 5-7\% от площади шлифа. Размер зерен и межзернового пространства оказался чрезвычайно мал при довольно хорошей сортировке (Рис. 8). Это объясняет, почему даже при высокой пористости наблюдается низкая проницаемость (Рис. 9). Петрофизические исследования капиллярометрии (методом полупроницаемой мембраны) позволили рассчитать размер поровых каналов и их долю. Рассчитанные данные были соотнесены с проницаемостью и гранулометрией. Это привело к выводу, что проницаемые 
интервалы приурочены к зонам с высоким объемным содержанием крупных пор, которые, в свою очередь, соответствуют зонам, сложенным относительно крупными частицами (Рис. 10). Это характерно для коллекторов порового типа.

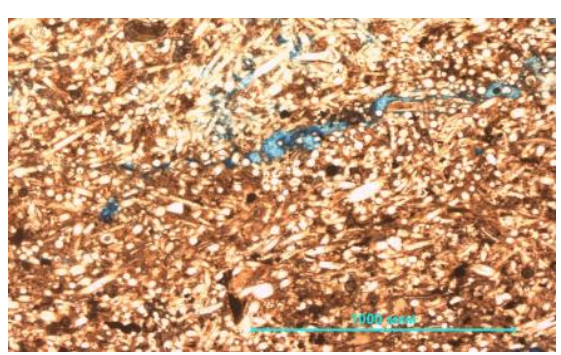

Рисунок 8 Спонголит в шилие.

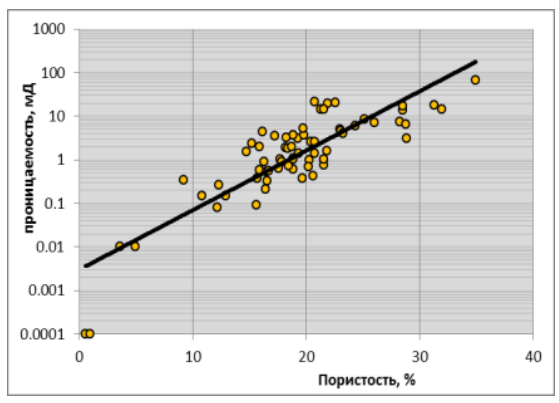

Рисунок 9 Зависимость Kn-Knp.

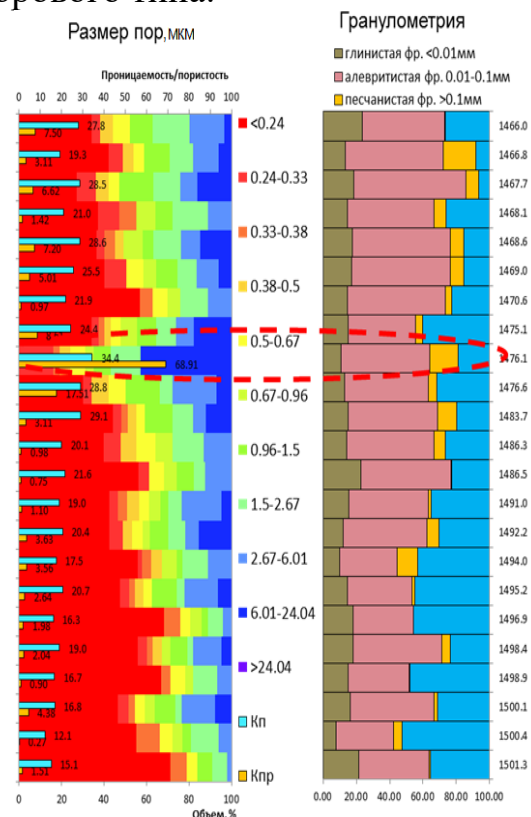

Рисунок 10 Сопоставление гранулометрия-размеры порKn-Knp.

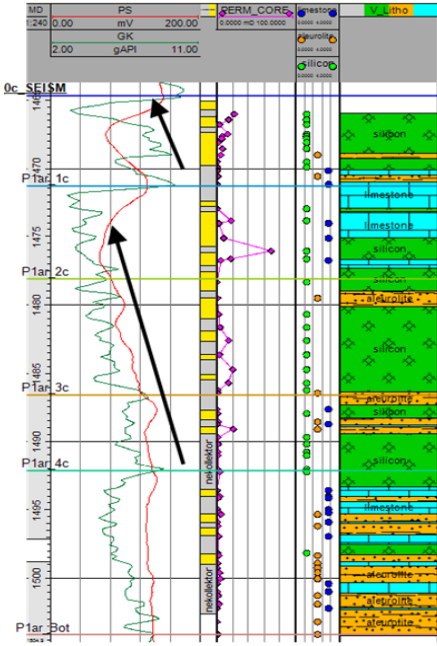

Литологическая колонка

силицит (кремн.)

Itimejtone Известняк (карб.)

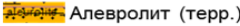

Рисунок 11 Литологическая колонка по скв. $130 E$.

Важно отметить малое количество и незначительную мощность проницаемых интервалов в пределах пласта, вскрытого скважиной $130 E$ (Рис. 11).

Из вышеизложенного следует наличие емкостного потенциала матрицы артинских отложений, прямое свидетельство этому - визуально отмечаемое насыщение на керне. Однако фильтрационный потенциал у матрицы очень низкий. Именно фильтрационный потенциал и может контролироваться сетью трещин, развитой в зонах тектонических деструкций, возникших за счет формирования кулисообразных разломов. Естественная трещиноватость в шлифах или по комплексу FMI не отмечена.

\section{Выводы}

В результате новых данных исследований керна артинских отложений установлено:

1. Коллектор терригенно-карбонатно-кремнистый, поровый, естественная трещиноватость не характерна, высокий емкостный и низкий фильтрационный потенциал коллектора обеспечивается маленькими размерами зерен и хорошей их сортировкой.

2. Выявленные по сейсмике 3D тектонические нарушения подтверждены бурением.

3. Зоны повышенной трещиноватости обеспечивают улучшенную работу скважин и связаны с напряженностью вдоль фронта сдвиговых и сбросовых нарушений.

4. Недостижение дебитов было обусловлено одновременно двумя факторами: 1 завышенный прогноз по результатам испытания разведок, попавших в зоны тектонических деструкций; 2 - использование утвержденной геологической модели, что привело к бурению в зоны с отсутствием тектонических нарушений, т.е. в слабопроницаемую матрицу и неправильному выбору ГТМ.

\section{Библиография}

1. Малышев Н.А. «Тектоника, эволюция и нефтегазоносность осадочных бассейнов европейского севера России», Сыктывкар 2000. 


\section{EAGE}

EUROPEAN

ASSOCIATION OF

NGINEERS

\section{References}

1. Malyshev N.A. «Tektonika, evolyutsiya i neftegazonosnost' osadochnykh basseynov yevropeyskogo severa Rossii», Syktyvkar 2000. 